\section{Comparison of Three RT-PCR Methods}

BioTechniques 25:230-234 (August 1998)

\begin{abstract}
Various approaches can now be taken for amplification of RNA transcripts using the polymerase chain reaction (PCR). Here, we compare three such methods: (i) uncoupled reverse transcription ( $R T$ )- $P C R$ (using separate reactions for $c D N A$ synthesis and PCR), (ii) continuous RT-PCR (in which RT and DNA amplification occur in an uninterrupted reaction) using either a single enzyme for both RT and DNA amplification or (iii) using two enzymes, one for each task. We have found that the continuous two-enzyme RT-PCR method is the most sensitive, followed by the uncoupled RT-PCR and then the continuous single-enzyme method. The continuous methods require less sample handling than the uncoupled method, and hence are less labor-intensive and less prone to contamination. The continuous single-enzyme method is the most expensive to perform in terms of reagents due to the quantity of DNA polymerase required; however, it does have advantages over the two enzyme methods in that the use of a thermostable enzyme for RT can alleviate certain problems by allowing $R T$ to occur at higher temperatures than those tolerable by viral reverse transcriptases.
\end{abstract}

\section{INTRODUCTION}

Reverse transcription polymerase chain reaction (RT-PCR) is a technique that is now commonly used for detection and measurement of gene expression, diagnosis of infectious agents or genetic diseases and generating cDNA for cloning.

The first protocols for RT-PCR used an "uncoupled" technique, wherein the target RNA was first copied into cDNA in an independent step using a reverse transcriptase. Following cDNA synthesis, the reaction product was diluted, the buffer conditions were changed to accommodate the requirements of Taq DNA polymerase and PCR was performed (5). To minimize the degree of sample handling (thus decreasing both labor intensity and risk of contamination), "continuous" RT-PCR protocols have been developed. In one version of continuous RT-PCR, the RT is still carried out by a dedicated reverse transcriptase and the PCR by Taq DNA polymerase; however, all the components necessary for both RT and PCR are present in the reaction tube at the outset. The reaction buffer is modified to permit activity of both reverse transcriptase and Taq DNA polymerase, and the RT and PCR are then carried out sequentially without interruption $(6,8,10)$. Another variation of continuous RTPCR makes use of the reverse transcriptase activity exhibited by some DNA polymerases (e.g., Tth DNA polymerase). Early applications using Tth DNA polymerase for RT-PCR were not strictly continuous because the reaction buffer needed to be modified between the RT and PCR steps. This was because Tth only displays reverse transcriptase activity in the presence of manganese ions, whereas magnesium ions are required for optimal DNA polymerase activity (7). This has been alleviated by the development of buffers that allow Tth to exhibit both reverse transcriptase and DNA polymerase activities, one of which uses bicine to buffer the metal ion concentration (11).

All three of these RT-PCR techniques are now used routinely, but, to date, there have been no reports directly comparing all three methods for their sensitivity and utility. Here, we compare these methods for detection of mRNA.

\section{MATERIALS AND METHODS}

\section{RNA Extraction}

RNA was extracted from the SK-mel 28 cell line (ATCC, Rockville, MD, USA) and from tumor tissue using the method described by Chomczynski and Sacchi (1), with the exception that tRNA was not added to the lysis buffer. The concentration of RNA was determined by spectrophotometry at $260 \mathrm{~nm}$.

\section{RT-PCR Method 1: Uncoupled RT-PCR}

cDNA synthesis was performed on total RNA extracted from the SK-mel
28 cell line. Tenfold dilutions of RNA from $13 \mathrm{ng} / \mu \mathrm{L}$ to $1.3 \mathrm{pg} / \mu \mathrm{L}$ were made, and $17 \mu \mathrm{L}$ of each dilution were heated to $70^{\circ} \mathrm{C}$ for $5 \mathrm{~min}$ with $1 \mu \mathrm{L}$ of random hexamers at $1 \mu \mathrm{g} / \mu \mathrm{L}$ (Promega, Madison, WI, USA). The tubes were then snap-chilled on ice, and the remainder of the reaction mixture was added, containing: $5 \mu \mathrm{L} 5 \times$ avian myeloblastosis virus reverse transcriptase (AMV-RT) buffer (Promega), $1 \mu \mathrm{L}$ dNTP mixture (each at $25 \mathrm{mM}$ ), $15 \mathrm{U}$ RNasin ${ }^{\circledR}$ and $10 \mathrm{U}$ AMV-RT (both from Promega), to a total volume of 25 $\mu \mathrm{L}$. The reactions were incubated for 1 $\mathrm{h}$ at $42^{\circ} \mathrm{C}$, then heated to $95^{\circ} \mathrm{C}$ for 10 min. Two microliters of the cDNA mixture were used in a PCR to detect hypoxanthine phosphoribosyl transferase (HPRT) mRNA. The PCR components were 5 pmol of each HPRT primer (sequences 5'-TCA ACA GGG GAC ATA AAA GTA AT-3' and 5'-GTC CTT TTC ACC AGC AAG CT-3'), $1 \mathrm{mM}$ $\mathrm{MgCl}_{2}, 1 \mathrm{U}$ AmpliTaq ${ }^{\circledR}$ DNA Polymerase (Perkin-Elmer, Norwalk, CT, USA) and $5 \mu \mathrm{L} 5 \times$ PCR Polymerization buffer (Fisher Biotec, Bayswater, VIC, Australia) resulting in final concentrations of: $(67 \mathrm{mM}$ Tris- $\mathrm{HCl}[\mathrm{pH}$ 8.8], $16.6 \mathrm{mM}\left[\mathrm{NH}_{4}\right]_{2} \mathrm{SO}_{4}, 0.45 \%$ Triton ${ }^{\circledR} \mathrm{X}-100,0.2 \mathrm{mg} / \mathrm{mL}$ gelatin and 0.2 $\mathrm{mM}$ dNTPs) in a final volume of 25 $\mu \mathrm{L}$. The PCR thermal cycle consisted of heating to $95^{\circ} \mathrm{C}$ for $5 \mathrm{~min}$, followed by 35 cycles of $95^{\circ} \mathrm{C}$ for $45 \mathrm{~s}, 55^{\circ} \mathrm{C}$ for $45 \mathrm{~s}$, and $72^{\circ} \mathrm{C}$ for $75 \mathrm{~s}$, with a final extension step of $7 \mathrm{~min}$ at $72^{\circ} \mathrm{C}$. PCR was also performed on $260 \mathrm{ng}$ of RNA, without prior cDNA synthesis, to indicate whether the RNA was contaminated with genomic DNA, which would result in an amplification product from HPRT pseudogenes (9).

\section{RT-PCR Method 2: Continuous RT-PCR, Two Enzymes}

The two-enzyme continuous RTPCR protocol contained the same reaction components as the PCR described above, with the inclusion of $0.5 \mathrm{U}$ AMV reverse transcriptase (AMV-RT) (Promega) and an alternative $5 \times$ reaction buffer, resulting in final concentrations of $67 \mathrm{mM}$ Tris- $\mathrm{HCl}$ ( $\mathrm{pH} 8.8$ ), 50 $\mathrm{mM} \mathrm{KCl}, 0.1 \%$ Triton $\mathrm{X}-100,6 \mu \mathrm{M}$ EDTA, $0.5 \mathrm{mM}$ dithiothreitol (DTT) and $0.1 \mathrm{mM}$ dNTPs. The same thermal 
cycling protocol was also used, with the inclusion of an incubation at $42^{\circ} \mathrm{C}$ for $30 \mathrm{~min}$ before the first PCR step. RT-PCR was performed on $2 \mu \mathrm{L}$ of tenfold dilutions of SK-mel 28 cell line RNA from $13 \mathrm{ng} / \mu \mathrm{L}$ to $1.3 \mathrm{pg} / \mu \mathrm{L}$.

\section{RT-PCR Method 3: Continuous RT-PCR, One Enzyme}

The single-enzyme RT-PCR was performed using rTth (Perkin-Elmer) for both RT and PCR. The procedure was carried out as per the instructions in the GeneAmp ${ }^{\circledR}$ EZ rTth RNA PCR Kit (Perkin-Elmer). The reaction mixture contained $2.5 \mathrm{U}$ rTth, $5 \mu \mathrm{L}$ of $5 \times$ EZ buffer (to final concentrations of 50 $\mathrm{mM}$ bicine, $115 \mathrm{mM}$ potassium acetate, $8 \%$ wt/vol glycerol, $\mathrm{pH} 8.2), 300 \mu \mathrm{M}$ each dNTP, $2.5 \mathrm{mM} \mathrm{Mn}(\mathrm{OAc})_{2}, 20$ pmol each primer in a total volume of $25 \mu \mathrm{L}$. RT-PCR was performed on $2 \mu \mathrm{L}$ of tenfold dilutions of SK-mel 28 cell line RNA from $13 \mathrm{ng} / \mu \mathrm{L}$ to $1.3 \mathrm{pg} / \mu \mathrm{L}$. The thermal cycling protocol consisted of incubation at $60^{\circ} \mathrm{C}$ for $30 \mathrm{~min}$, heating to $95^{\circ} \mathrm{C}$ for $2 \mathrm{~min}$, then performing 35 cycles of a two-step protocol: $55^{\circ} \mathrm{C}$ for $1 \mathrm{~min}$ for annealing and extension and $95^{\circ} \mathrm{C}$ for $1 \mathrm{~min}$ for denaturation, followed by a final extension for $7 \mathrm{~min}$ at $60^{\circ} \mathrm{C}$.

\section{Gel Electrophoresis}

RT-PCR products were electrophoresed on a $2 \%$ agarose gel, stained with ethidium bromide and photographed under UV transillumination.

\section{RESULTS}

\section{Sensitivity of RT-PCR}

The sensitivities of all three RT-PCR methods were compared using dilutions of total RNA extracted from the SK-mel 28 cell line as target. Using method 1 (uncoupled RT-PCR), HPRT mRNA could be detected in dilutions of RNA down to $130 \mathrm{pg} / \mu \mathrm{L}$. Using method 2 (two-enzyme continuous RT-PCR) the detection limit was $13 \mathrm{pg} / \mu \mathrm{L}$. Using method 3 (one-enzyme continuous RTPCR), a very faint band was visible on the original gel at $130 \mathrm{pg} / \mu \mathrm{L}$ (Figure 1). No amplification product was seen after direct PCR of RNA samples (no RT step), hence products seen after RTPCR must be derived from HPRT mRNA and not HPRT pseudogenes.

\section{DNA Polymerase Activity of rTth}

To determine whether the reduced sensitivity seen with the rTth method was due to less-efficient reverse transcriptase activity or DNA polymerase activity, the DNA polymerase activity of rTth was assessed. cDNA was synthesized from $2.2 \mu \mathrm{g}$ RNA extracted from the SK-mel 28 cell line, and fivefold dilutions of the cDNA were made down to a $5^{-5}$ dilution. Two microliters

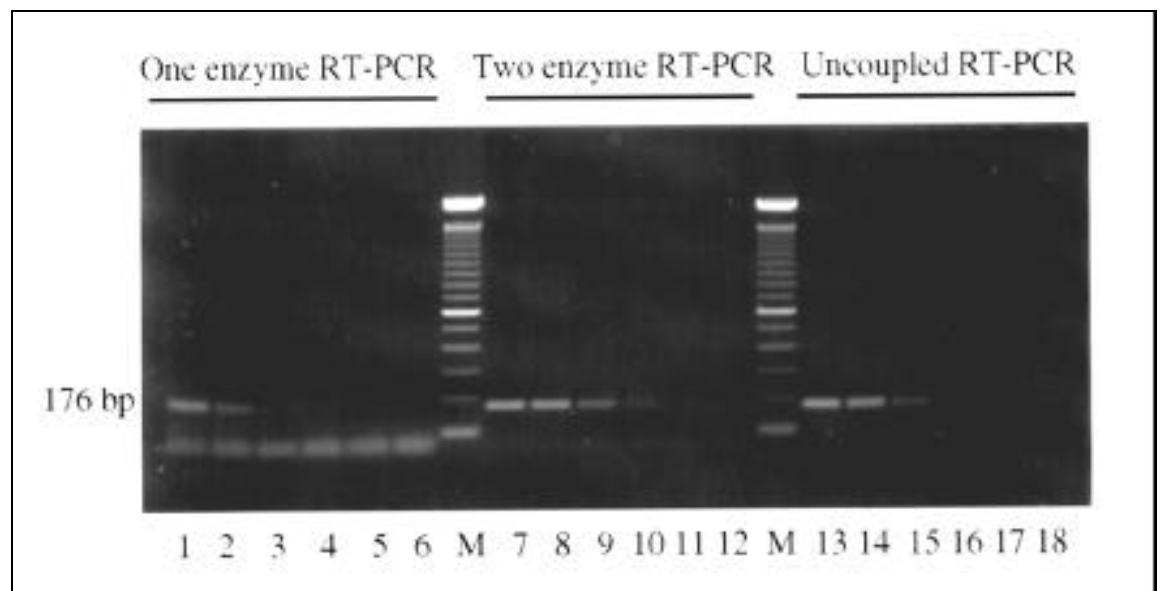

Figure 1. Comparison of the sensitivity of three RT-PCR methods for detection of HPRT mRNA. RT-PCR was performed on RNA extracted from SK-mel 28 cell line at concentrations of 13000,1300 , $130,13,1.3$ and $0 \mathrm{pg} / \mu \mathrm{L}$ (negative control). Lanes 1-6: one-enzyme continuous RT-PCR using $\mathrm{r}$ Tth. Lanes 7-12: two-enzyme continuous RT-PCR using AMV-RT and AmpliTaq. Lanes 13-18: uncoupled RT-PCR. M: mol wt marker (100-bp DNA ladder; Life Technologies, Gaithersburg, MD, USA). 


\section{Short Technical Reports}

of each dilution were subjected to DNA amplification by AmpliTaq using method 1 (PCR component only), and by rTth using RT-PCR method 3, without the initial incubation at $60^{\circ} \mathrm{C}$ for 30 min. The sensitivity of detection of cDNA by rTth matched that of AmpliTaq, with both enzymes able to detect cDNA down to the $5^{-3}$ dilution.

\section{Reliability and Sample-to-Sample Variation}

RNA was extracted from approximately $50 \mathrm{mg}$ of nine different breast tumor samples and resuspended in $30 \mu \mathrm{L}$ of water. The concentration of RNA varied between samples from 300-1650 $\mathrm{ng} / \mu \mathrm{L}$. All samples were adjusted to a concentration of $300 \mathrm{ng} / \mu \mathrm{L}$, and $1 \mu \mathrm{L}$ of each was subjected to RT-PCR using methods 2 and 3, as well as method 1 (PCR only), to check for genomic DNA contamination. Using method 2 (AMVRT and AmpliTaq), all samples produced a distinct band of the correct molecular weight, and all bands were of similar intensity. Using method 3 (rTth), all samples produced a distinct band of the correct molecular weight, although some bands appeared weaker than others. Repeating this experiment on a $1 / 10$ dilution of each RNA sample (i.e., 30 ng RNA per reaction) resulted in two of the samples failing to produce a visible product using method 3 (rTth), while all samples still produced a visible product using method 2 (AMV-RT and AmpliTaq) (Figure 2). No PCR products were produced from the RNA samples without prior RT, indicating that amplification of pseudogenes due to genomic DNA contamination did not occur.

\section{DISCUSSION}

When choosing an RT-PCR method, the selection criteria may include sensitivity, specificity, fidelity, robustness, speed, contamination risk and cost in varying degrees of importance depending on the application. In this paper, we have investigated and compared the sensitivity and resilience of the three most commonly used RT-PCR methods.

The sensitivities of these methods were compared using primers designed to amplify mRNA of the HPRT gene from total RNA. The continuous two-enzyme method (AMV-RT and AmpliTaq DNA polymerase) was found to be the most sensitive-achieving sensitivity 10-fold higher than the uncoupled method and 10-fold to 100-fold higher than the one-enzyme (rTth) continuous method. The observed advantage of a two-enzyme (AMV-RT and Taq DNA polymerase) continuous method over a discontinuous procedure is consistent with a previous report (6). It was suggested this may have been due to increased mispriming and formation of secondary RNA structures during cooling to $42^{\circ} \mathrm{C}$ for RT in the uncoupled procedure, which did not occur in the continuous method, as samples were heated to $60^{\circ} \mathrm{C}$ then cooled only to $50^{\circ} \mathrm{C}$ for RT (6). In our study, RT was carried out at $42^{\circ} \mathrm{C}$ for both uncoupled and continuous methods, and samples were not heated to denature RNA before RT in the continuous method. Thus, the inferior sensitivity of the uncoupled method is unlikely to be due to excessive RNA secondary structure.

The observed advantage of the uncoupled method over the continuous rTth procedure has been previously described (2), although in these instances Moloney murine leukemia virus reverse transcriptase (MMLV-RT) was used instead of AMV-RT. Interestingly, although Juhasz et al. (3) found that RT-PCR of actin mRNA was more sensitive using the two-enzyme system, they found that RT-PCR of tyrosinase mRNA was less sensitive. This was ascribed to the fact that the primers used for the tyrosinase RT-PCR had stable hairpin loop structures with melting temperatures higher than that used for reverse transcription by MMLV-RT. However, reverse transcription at a higher temperature with $\mathrm{r} T$ th resulted in melting of the hairpin loops, thus increasing the efficiency of reverse transcription and hence the sensitivity of the RT-PCR.

The observed superior sensitivity of the two-enzyme continuous RT-PCR over the one-enzyme (rTth) continuous RT-PCR has not, to our knowledge, been published previously. A similar result was obtained using a different primer set to amplify Ross River virus RNA (results not shown). Hence, we believe this disparity in sensitivity between the two systems to be a general effect, barring strong RNA target secondary structure or primer hairpins, which may benefit from the higher temperatures used in the rTth protocol. Increasing the amount of Tth from 2.5-5 $\mathrm{U}$ per reaction or increasing the cycle number from 35-40 did not improve the sensitivity of mRNA detection in our hands (results not shown). The greater sensitivity of RT-PCR methods using viral reverse transcriptases is probably due largely to the higher efficiency of RT exhibited by these enzymes in comparison to rTth, since rTth and AmpliTaq were found to have comparable DNA polymerase activity.

The two-enzyme RT-PCR appeared to be more robust and less affected by sample variation in RNA quality than the rTth RT-PCR, as more consistent results were obtained using the two-enzyme method on a series of RNA samples extracted from tumor tissue that were adjusted to equal RNA concentrations. Although the RNA concentra-

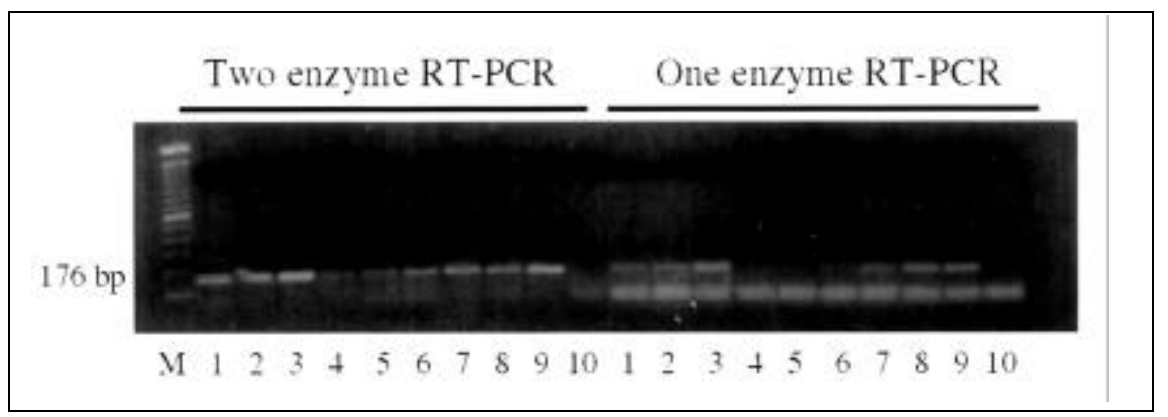

Figure 2. Sample-to-sample variation in two-enzyme and one-enzyme continuous RT-PCR. RTPCR was performed on RNA extracted from breast tumors at 30 ng RNA per reaction. Lanes 1-9: breast tumor RNA reactions. Lane 10: negative control (no RNA). Left-hand set: two-enzyme continuous RTPCR using AMV-RT and AmpliTaq. Right-hand set: one-enzyme continuous RT-PCR using rTth. M: mol wt marker (100-bp DNA ladder; Life Technologies). 
tions were the same as determined by optical density, this does not necessarily mean that there were equal numbers of HPRT transcripts to be amplified in each sample. This is because of the following: ( $i$ ) we have assumed, but not proven, that HPRT is expressed equally in all tissue samples, and (ii) RNA may be more degraded in some samples than others, so although it may contribute to optical density, it may not actually be amplifiable in the RT-PCR. Thus, although variable performance of the $\mathrm{rTth}$ method at the same RNA concentrations may at first glance be assumed to be because of differences in RNA quality or reaction inhibitors carried over during the RNA extraction process, it may in fact be because of decreased sensitivity. This is somewhat supported by the fact that dilution of the samples that initially produced fainter bands at $300 \mathrm{ng}$ per reaction in the $\mathrm{r}$ Tth method gave a poorer result at $30 \mathrm{ng}$ per reaction. One might expect that if inhibitors were present, diluting the sample would improve the result. Interestingly, Tth has been found to be more tolerant of the presence of phenol than is Taq DNA polymerase in PCR (4).

With regards to DNA replication fidelity, neither $\mathrm{r} T$ th nor AmpliTaq are particularly high-fidelity DNA polymerases, and in a continuous RT-PCR protocol, the fidelity of $\mathrm{rTth}$ would be further reduced due to the presence of $\mathrm{Mn}^{2+}$. For best results in cloning, higher fidelity enzymes such as $\operatorname{Vent}_{R^{\circledR}}$ DNA polymerase (New England Biolabs, Beverly, MA, USA) or ULTma ${ }^{\mathrm{TM}}$ DNA polymerase (Perkin-Elmer) are generally recommended.

One feature of rTth is that it is thermostable, allowing the RT to be done at $60^{\circ} \mathrm{C}$ or more. This has two potential advantages. First, the specificity of the RT can be improved if site-specific oligonucleotides are used to prime the RT. The second advantage of using a higher temperature for RT is that RNA secondary structures will be relaxed, which can overcome read-through problems that can occur when reversetranscribing at lower temperatures. AMV-RT is thermo-resistant and can withstand a short incubation at $65^{\circ} \mathrm{C}$ to improve site-specific oligonucleotide binding and reduce RNA secondary structures before RT at $50^{\circ} \mathrm{C}(6)$.
Given a situation in which sensitivity is a high priority, the two-enzyme continuous RT-PCR protocol may be the method of choice since it also has added benefits in that $(i)$ less sample manipulation is required than the discontinuous method, which reduces the labor-intensity and the risk of contamination, and (ii) it is the least expensive in terms of reagents if only one RTPCR needs to be applied to each RNA sample. However, if multiple RT-PCRs are to be performed on each RNA sample and maximal sensitivity is not required, it may be more appropriate to use the uncoupled method. This is because the extra cost incurred in performing a separate cDNA synthesis is distributed over multiple PCRs, and the sample is more safely stored as cDNA rather than to risk progressive RNA degradation by multiple freeze-thaws of sample RNA. The two-enzyme procedures also have an advantage over the one-enzyme method in that it is easy to test for genomic DNA contamination, which can cause spurious results if pseudogenes are amplified by simply omitting the reverse transcriptase in a parallel reaction. Using a one-enzyme method, one can never be sure whether the PCR product was generated from RNA or contaminating genomic DNA if pseudogenes exist.

In conclusion, several factors must be taken into consideration when selecting a method for RT-PCR, and the relative importance of these will vary depending on the application.

\section{REFERENCES}

1.Chomczynski, P. and N. Sacchi. 1987. Single-step method of RNA isolation by acid guanidinium thiocyanate-phenol-chloroform extraction. Anal. Biochem. 62:156-159.

2.Cusi, M.G., M. Valassina and P.E. Valensin. 1994. Comparison of M-MLV reverse transcriptase and Tth polymerase activity in RTPCR of samples with low virus burden. BioTechniques 17:1034-1036.

3.Juhasz, A., S. Ravi and C.D. O'Connell. 1996. Sensitivity of tyrosinase mRNA detection by RT-PCR:rTth DNA polymerase vs. MMLV-RT and AmpliTaq ${ }^{\circledR}$ polymerase. BioTechniques 20:592-600.

4.Katcher, H.L. and I. Schartz. 1994. A distinctive property of Tth DNA polymerase: enzymatic amplification in the presence of phenol. BioTechniques 16:84-92.

5.Kawasaki, E.S. and A.M. Wang. 1989. Detection of gene expression, p. 89-98. In H.A 


\section{Short Technical Reports}

Erlich (Ed.), PCR Technology. Stockton Press, Hampshire, UK.

6.Mallet, F., G. Oriol, C. Mary, B. Verrier and B. Mandrad. 1995. Continuous RT-PCR using AMV-RT and Taq DNA polymerase: characterization and comparison to uncoupled procedures. BioTechniques 18:678-687.

7.Myers, T.W. and D.H. Gelfand. 1991. Reverse transcription and DNA amplification by a Thermus thermophilus DNA polymerase. Biochemistry 30:7661-7666.

8.Sellner, L.N., R.J. Coelen and J.S. Mackenzie. 1992. A one-tube, one manipulation RTPCR reaction for detection of Ross River virus. J. Virol. Methods 40:255-264.

9.Sellner, L.N. and G.R. Turbett. 1996. The presence of a pseudogene may affect the use of HPRT as an endogenous mRNA control in RT-PCR. Mol. Cell. Probes 10:481-483.

10.Xu, L., D. Harbour and M.A. McCrae. 1990. The application of the polymerase chain reaction to the detection of rotaviruses in faeces. J. Virol. Methods 27:29-38.

11.Young, K.K.Y., R.M. Resnick and T.W. Myers. 1993. Detection of hepatitis C virus RNA by a combined reverse transcription-polymerase chain reaction assay. J. Clin. Microbiol. 31:882-886.
Address correspondence to Dr. Loryn N. Sellner, Department of Pathology, Royal Perth Hospital, Wellington St., Perth, WA, 6000, Australia. Internet: loryn.sellner@ rph.health.wa.gov.au

Received 29 October 1997; accepted 25 March 1998.

Loryn N. Sellner and Gavin R. Turbett

Royal Perth Hospital

Perth, WA, Australia

\section{Simultaneous Synthesis of Partially Homologous Oligonucleotide Sequences}

BioTechniques 25:234-238 (August 1998)

\begin{abstract}
A technique is described that allows the concurrent synthesis of homologous regions of separate oligonucleotides. The technique utilizes synthesis columns that are readily interconverted between single-chambered and dual-chambered. The regions of the oligonucleotides that differ are synthesized separately with single-chamber columns, and with the single modules joined, the homologous regions synthesized simultaneously. After synthesis, the chambers are opened separately, the solid-phase-bound oligonucleotides are placed in deprotection vials and treated as normal. Compared with standard syntheses, no decrease in yield or oligonucleotide quality was observed. This technique can result in significant savings in time and reagent costs when synthesizing a series of homologous oligonucleotides. This technique could be extended to the simultaneous synthesis of more than two oligonucleotides, possibly up to four or five oligonucleotides in an appropriate multichambered column.
\end{abstract}

\section{INTRODUCTION}

The synthesis of oligonucleotides by the phosphoramidite method (5) is now a well-established and accepted technique for the synthesis of both DNA and RNA oligonucleotides. Oligonucleotides are synthesized from the $3^{\prime}$ end, beginning with a solid-phasebound protected nucleoside and the oligonucleotide built up sequentially by addition of protected nucleoside phosphoramidites. In our laboratory, we occasionally have the need to synthesize a number of partially homologous oligonucleotides, for example, a series of primers with identical tag sequences at one end or a series of RNA oligonucleotides incrementing in length for ribozyme cleavage studies (8). It has been possible to synthesize oligonucleotides with identical $3^{\prime}$ ends and differing $5^{\prime}$ ends simply by interrupting the synthesis at the point where the sequences diverge, dividing the solidphase-bound oligonucleotides into two or three new columns and continuing each synthesis separately. Clearly, this approach is not applicable to oligonucleotides that differ at their $3^{\prime}$ ends, unless the end user required both sequences in the same solution, as in a polymerase chain reaction (PCR). Here, we demonstrate how a simple column with two reaction chambers allows the simultaneous synthesis of homologous regions of two oligonucleotides, where the regions of homology may reside in any part of the oligonucleotides.

\section{MATERIALS AND METHODS}

\section{Construction of Column}

The standard snap-type column as supplied pre-packed by PE Applied Biosystems (Foster City, CA, USA) has 5 separate components; shown in exploded view in Figure 1. The reaction chamber is formed within the central connector enclosed at each end by the frits. Within the end caps are female luer fittings for the attachment of the delivery lines. The dual-chambered column (DCC), constructed using only components from the standard column, is shown in Figure 1. Three standard disposable columns are required to make the DCC. First, a standard frit (f6.6) is trimmed from the standard 6.6- 